\title{
El alma colombiana. Idiosincrasia e identidades culturales en Colombia*
}

\author{
P. Pedro José Díaz Camacho, O.P.**
}

Recibido: 14 de noviembre de 2011 Evaluado: 26 de enero de 2012 Aceptado: 10 de febrero de 2012

\section{RESUMEN}

La presente investigación tiene el propósito de averiguar sobre los rasgos anímicos y temperamentales que se expresan en el modo de ser y en la conducta de los colombianos, según las distintas regiones y grupos socioculturales; es decir, sobre cómo ha llegado a ser en el siglo XXI la índole y el alma del pueblo colombiano.

Bajo este panorama, se indaga acerca de algunos factores que intervienen en la configuración y expresión del modo de ser, pensar, sentir, percibir y actuar de los colombianos, junto con la forma diversa como se manifiesta su idiosincrasia y la identidad cultural, según lo expuesto por algunos estudiosos de las cuestiones antropológicas, históricas y sociológicas del pueblo colombiano.

\section{Palabras clave}

Cultura, diversidad, fenomenología, identidad, idiosincrasia, interpretación, ethos. 


\title{
Colombian Soul. Idiosyncrasies and Cultural Identities in Colombia
}

\author{
P. Pedro José Díaz Camacho, O.P.
}

\section{Abstract}

This research aims to ascertain the mood and temperamental traits which are expressed in the Colombians' way of being and behaving. This is done by taking into account different regions and cultural groups. In other words, this work tracks how the Colombian people's nature and soul have evolved in the 21st century.

In this scenario, some of the factors involved in the shaping and expression of the Colombians' way of being, thinking, feeling, perceiving and behaving are explored. The different ways in which they manifest their idiosyncrasies and cultural identity are also examined. All of which is in accordance with research done by experts on anthropological, historical and sociological issues regarding Colombian people.

\section{KeYWORDS}

Culture, diversity, phenomenology, identity, idiosyncrasies, interpretation, ethos. 
Nosotros somos un pequeño género humano...

Carta de Jamaica

Simón Bolívar (1816)

A nivel de ADN, todos somos un 99.9 por ciento idénticos. Esa similitud es aplicable sin importar qué dos individuos de todo el mundo elijamos comparar.

Francis S. Collins (2009, p. 138)

\section{INTRODUCCIÓN}

Nuestra historiografía moderna ha dedicado notable atención

a la naturaleza de las regiones en Colombia, y ha contribuido así a un mejor entendimiento de la composición plural del país...

La búsqueda de la colombianidad en los últimos años

ha resultado en sustanciales redefiniciones de la nación,

en las que, de manera creciente y sin mayor discusión,

se han impuesto los discursos que enfatizan

sus componentes étnico-culturales por encima de los políticos.

Eduardo Posada Carbó (2006)

Para precisar el sentido de lo que aquí se indaga, podemos plantearnos algunas preguntas. ¿Cuáles son los principales factores étnicos y antropológicos que inciden en la forma de ser y de comportarse los colombianos, o cuáles pueden estar en más estrecha relación con su fenomenología sociocultural?, ¿qué rasgos anímicos y temperamentales están más relacionados con el ethos y la conducta de los colombianos?, ¿qué expresiones de la idiosincrasia colombiana se reconocen con más frecuencia y relevancia en los diversos campos de la vida y de la actividad social y cultural, así como en los comportamientos de los grupos humanos, a lo largo de la historia?
Los colombianos, en general, aún no tenemos ideas claras y definidas sobre lo que somos y cómo somos, en términos de carácter o modo de ser. Se suelen emplear estereotipos y generalizaciones sobre la idiosincrasia de los colombianos, resaltando más los aspectos negativos de la conducta, pero sin profundizar en lo medular y la esencia del ser colombiano; hasta dónde es posible esta pretensión. Inicialmente podemos decir que el alma del colombiano se parece a la compleja morfología de su ámbito geográfico, a la variedad de sus climas, a la diversidad de géneros y ritmos musicales cultivados en las distintas regiones, así como a sus apasionantes vicisitudes históricas y sociales: como su paisaje, compuesto de cordilleras majestuosas y ríos caudalosos, valles inmensos, precipicios indescifrables y selvas inhóspitas, así, muy compleja y diversa, se ha configurado el alma del colombiano, según su origen racial, los procesos de mestizaje y migración, su hábitat, su contexto sociocultural y los influjos externos.

A este tipo de cuestiones nos aproximamos desde el ámbito de las ciencias del hombre y dentro de las narrativas socioculturales y hermenéuticas, con la advertencia de que no se intenta hacer un estudio sistemático ni exhaustivo de la psique colombiana, ni se pretende deducir un posible prototipo antropológico que defina al colombiano modélico y uniforme, sino de aproximarnos a algunos rasgos manifestativos de su alma, su temperamento, su carácter y su idiosincrasia, en orden a comprender mejor la diversidad de su ethos y su identidad cultural, teniendo en cuenta que es difícil establecer de manera tajante y definitiva denominadores comunes para caracterizar conglomerados humanos hoy bastante heterogéneos y en proceso constante de mestizaje, 
movilidad e integración, debido, entre otras causales, al influjo creciente de diversas culturas foráneas a través de las dinámicas de la globalización y los procesos que generan los diversos medios de comunicación social.

En el presente trabajo se trata sobre algunos aspectos que intervienen en la configuración del modo de ser, de pensar, de sentir, de percibir y de actuar de los colombianos y la forma como se expresa su idiosincrasia en la conducta social. De la mano de algunos estudiosos de las cuestiones antropológicas, históricas y sociológicas queremos acercarnos a los rasgos del temperamento y del carácter de los colombianos, a algunas de sus virtudes y de sus vicios, con el fin de comprender de una manera más integral el fenómeno sociocultural colombiano en cuanto se expresa en comportamientos más o menos típicos y formas temperamentales arraigadas y constantes, en torno a lo que se entiende bajo el concepto de identidad cultural e idiosincrasia. Para ello, se ha hecho una revisión bibliográfica de los componentes temáticos implicados, teniendo en cuenta los pocos estudios recientes sobre la idiosincrasia (o idiosincrasias e identidades culturales colombianas), desde el punto de vista de la pluriculturalidad y multietnicidad que se reconoce en Colombia, en sus diversos grupos regionales, como lo ha recogido y expresado la misma Constitución Política de Colombia (1991) al hablar de la diversidad étnica y cultural de la nación (Artículo 7).

Dado que el componente religioso católico aún sigue influyendo en el pueblo colombiano como factor cultural unificador de la diversidad que se da en otros ámbitos, parece conveniente mencionar inicialmente el factor religioso y su papel determinante en los procesos históricos y sociales; en este sentido se puede afirmar que, en la configuración del alma colombiana, se ha dado una influencia significativa, sobre todo a través de los imperativos morales y de los procesos de inculturación, porque la religión inculca valores, modela conductas y costumbres, señala pautas de comportamiento $\mathrm{y}$ modos de ser y proceder individual y colectivamente. Como bien lo ha expresado, para el ámbito regional latinoamericano, Manuel Marzal, a propósito del catolicismo popular que, en cuanto sistema cultural,
imprime en las personas que lo viven un conjunto de disposiciones o fuer- zas psicológicas características, a sa- ber 'estados de ánimo' peculiares, que acompañan a la persona, y una serie de 'motivaciones', que le orientan a la práctica. Tales disposiciones son pro- fundas y duraderas, prestan un carác- ter estable a la experiencia popular y forman lo que se ha llamado el 'senti- miento religioso' del pueblo (Marzal, 1976, pp. 131-132).

De manera semejante, la idiosincrasia personal y grupal aporta ciertas connotaciones peculiares a la experiencia religiosa y a su expresión como religiosidad popular. Esta acción de doble vía y sentido, a modo de interacción dialéctica, ha de ser tenida en cuenta y valorada debidamente para lograr una comprensión adecuada e integral del catolicismo popular colombiano y de otras expresiones socioculturales de los grupos humanos que conforman la nación. Dicha consideración parece especialmente importante y necesaria si tenemos en cuenta la complejidad de la realidad social y cultural de un pueblo y nación cuya historia es aún reciente.

La forma sociocultural de expresarse un pueblo implica o posibilita una religiosidad 
con determinadas características y énfasis en su configuración y en su dinamismo, a la vez que el cultivo de un tipo de creencias y prácticas de religiosidad con peculiares matices o tendencias modela igualmente una determinada forma de ser y de comportarse en otros campos de la vida. No se quiere decir, sin embargo, que esta mutua interacción de diversas dimensiones y niveles de la experiencia humana obedezca o suceda de una manera determinista y ciega, ya que en este campo, como en toda experiencia humana, hay otros factores y causas influyentes y condicionantes, como sucede con el modo de comprender y asumir la libertad, los intereses individuales y grupales, las condiciones y procesos históricos, las motivaciones, las diversas experiencias de los grupos humanos, el influjo de las ideologías, tendencias y movimientos de otros países, y la misma cosmovisión.

Para aclarar el sentido y alcance de los interrogantes que nos hemos planteado, queremos aproximarnos a lo que se ha denominado como idiosincrasia colombiana, desde el ámbito de las ciencias del hombre y dentro de las narrativas socioculturales, con las limitaciones y la finalidad propia del presente estudio en torno a la identidad cultural y la idiosincrasia del pueblo colombiano; lo hacemos acercándonos y releyendo algunos estudios que se han hecho sobre el hombre colombiano, su carácter y su modo de ser ${ }^{1}$.

1 A este propósito recordamos que el Episcopado colombiano ha advertido en distintas oportunidades sobre la necesidad de hacer este tipo de estudios acerca del hombre colombiano y sobre las culturas autóctonas como presupuesto indispensable para el desarrollo de la misión evangelizadora (Conferencia Episcopal de Colombia, 1981) La Iglesia ante el cambio. XXV Asamblea Plenaria del Episcopado Colombiano, 1969 (3a ed.), №. 152 y 153, a modo de ejemplo. Cf. Constitución Política de Colombia, 1991, art. 70; Ardila, R. (1986). Psicología del hombre colombiano. Cultura y comportamiento social, Bogotá: Planeta. Debo advertir a los lectores que la presente investigación amplía y actualiza una parte de la indagación que se había
Como ya hemos advertido, no se trata de hacer un estudio sistemático ni exhaustivo de lo que implica la idiosincrasia de un pueblo y de los distintos grupos humanos que lo componen, sino de indagar sobre los componentes y factores antropológicos, sociales y culturales más notables y comunes, por decirlo de alguna manera, en orden a comprender mejor su ethos y su identidad cultural $^{2}$. También hay que tener en cuenta que algunas consideraciones tendrán más aplicabilidad en unas regiones del país que en otras, por lo cual las generalizaciones que se hacen, se han de tomar con algunas reservas, aunque nos mantengamos particularmente circunscritos al ámbito geocultural andino colombiano y haya razones fundadas para proponer algunas generalizaciones de reconocida validez para hablar de la identidad cultural y de la idiosincrasia del pueblo colombiano ${ }^{3}$.

iniciado a propósito de la tesis doctoral en Teología sobre el catolicismo popular en los Andes colombianos. Hacia una hermenéutica teológica global (Salamanca, 1986, pp. 305-343), texto que no ha sido publicado.

2 Aunque en este estudio utilicemos algunos términos que tienen un sentido técnico en el ámbito de las ciencias humanas, tendremos en cuenta su uso corriente y su significación analógica sin detenernos en precisiones 0 análisis semánticos más especializados. Así ocurre al hablar de temperamento, carácter, alma, personalidad y ethos, entre otros.

3 Cuando tratamos de los presupuestos socioantropológicos o elementos triétnicos que entraron en juego en nuestra composición racial, como rasgos de nuestra herencia que no hay que olvidar, se hallan constantemente referidos en los distintos estudios consultados en el presente trabajo. Cf. López de Mesa, L. (1970c, pp. 75106; 1970a, pp. 65-124), Ballesteros, M. (1985, pp. 87-94), Yunis, E. (2003), entre otros estudios. Cf. Constitución Política de Colombia, 1991, artículos 9 y 10. 


\section{LO ANDINO-CARIBE COMO CONTEXTO Y CATEGORÍA DE IDENTIDAD CULTURAL, EN CLAVE SOCIOLÓGICA}

Los vientos que corrieron por los bellos países donde el verde es de todos los colores, los vientos que cantaron por los países de Colombia.

Aurelio Arturo

Los estudiosos de la condición humana han asociado el modo de ser de las personas y grupos humanos a su entorno geográfico, climático y cultural, como lo expresó en su momento Aristóteles, por traer un ejemplo de una época bastante remota, citado, además, por Tomás de Aquino, a propósito de las habilidades de los pobladores de algunas regiones para las ciencias, las artes y la guerra.

Los pueblos que habitan las regiones frías ciertamente son valientes, pero algo deficientes en ciencias y artes; por lo mismo viven más tiempo disgregados. No viven políticamente, y tampoco pueden convivir con sus vecinos por su imprudencia. Los que habitan en lugares tórridos, ciertamente son más desarrollados intelectual y artísticamente según el espíritu, pero no tienen valentía; por lo mismo más fácilmente se les subyuga, y así permanecen. Mas, quienes viven en climas templados participan de ambas cualidades; por lo que perseveran más como hombres libres, viven la más alta vida política, y saben gobernar sobre otros (De Aquino, 2003, L. II, cap. I, pp. 61-62) ${ }^{4}$.

4 Este tipo de afirmaciones se ha exagerado en algunos casos para expresar la supremacía de unas razas sobre otras, con toda la carga negativa que ello ha tenido en la historia humana. Por eso es necesario relativizar lo que pueda sugerir cualquier clase de determinismo, especialmente en un mundo globalizado y con pocas fronteras socioculturales, como sucede en la actualidad (Yunis, 2003, p. 55). El libertador Simón Bolívar, en la Carta de Jamaica (1816), hablaba también de cómo climas remotos, situaciones diversas, intereses opuestos, caracteres desemenjantes, dividen a la América.
A lo largo del presente estudio aparecerán referencias parecidas a la impronta que marca el contexto geográfico y ecológico sobre el espíritu y modo de ser de las personas y de los grupos humanos. Para nuestro caso, debemos afirmar inicialmente que la cultura colombiana es caribeña y andina a la vez, aunque no exclusivamente, y en conjunción y mestizaje complejo. Por esta condición, es necesario considerar esas dos vertientes y contextos cuando se trata de analizar la realidad social y cultural del pueblo colombiano en torno a su identidad e idiosincrasia, para comprender mejor el modo de ser de la gente. "Colombia fue desde siempre un país de identidad caribe abierto al mundo por el cordón umbilical de Panamá. La amputación forzosa nos condenó a ser lo que hoy somos: un país de mentalidad andina" (García Márquez, 2002, p. 538) 5 .

\section{¿Cómo son los colombianos? Una visión global aproximativa}

En el momento hay un número significativo de estudios publicados en los que se ha tratado de responder este interrogante, como se puede apreciar en la muestra bibliográfica y en las constantes referencias a pie de página.

Pretender expresar en pocas páginas cómo son los colombianos, encierra cierto grado de temeridad y un peligro de generalización indebida, pero el intentarlo nos puede dar también la oportunidad de hacer una aproximación socioantropológica que luego se tratará de desarrollar y profundizar un poco más. A este propósito, el profesor Luis López de Mesa (1884-1967), gran conocedor e intérprete del ser colombiano, en sus

5 En distintos pasajes de sus obras, García Márquez hace este tipo de referencias sobre la condición caribeño-andina de los colombianos. 
múltiples y complejas vertientes y en su devenir histórico, propone esta apreciación global:

\begin{abstract}
Si se me pidiese un resumen de las cualidades más salientes del colombiano, diría que es idealista con marcada inclinación al lirismo, universalista con amor al progreso, pacifista con tendencia al orden, hospitalario por simpatía y vocación democrática (López de Mesa, 1970a, p. 71) ${ }^{6}$.
\end{abstract}

Apelando a algunos factores hereditarios provenientes de nuestra peculiar mezcla racial y desde el punto de vista de las pasiones anímicas, parecen pertinentes las siguientes consideraciones aproximativas de Abel Naranjo Villegas (1965):

Las pasiones colombianas tienen los elementos arábigo-españoles, la soberbia, la magnificencia, la envidia, la petulancia, la discreción, originaria del indígena. Sin embargo, esas pasiones no son las mismas porque la aleación casi química y su conjugación con las peculiares circunstancias de nuestro proceso antropológico e histórico han derivado en un producto nuevo que debemos meditar y al cual aludían ya hasta los cronistas y viajeros ilustres como Humboldt.

Esas pasiones, subsuelo de la cultura que ofrecemos, es difícil precisarlas, ya que están matizadas con los mismos elementos hereditarios, con las mezclas y combinaciones raciales, con las influencias recibidas, con la situación geográfica y con la manera cómo funcionan al accionar inconscientemente en las categorías de una triple tradición que se ha ido estratificando en el interior de nuestra vida social. Pero hay que contar

6 Dice, además, en otra de sus obras: "El colombiano es hospitalario y bondadoso, amante de la cultura y del orden, aunque carece aún de la reciedumbre de una disciplina personal eficiente" (1970b, p. 414). A este autor nos referiremos con frecuencia, dada la vigencia de sus análisis sobre la realidad social y cultural del pueblo colombiano. con ellas porque condicionan, originan y modifican nuestro horizonte vital (pp. 254-255) ${ }^{7}$.

Explicitando un poco más estos conceptos, el mismo autor dice que el pueblo colombiano posee un sustrato más bien anímico que espiritual en el que prevalece la emotividad sobre la visión clara de los objetos hacia los cuales aspira; dotado de mucho más temperamento que de carácter, cuya filosofía educativa ha apuntado más hacia el alma que al espíritu estimulando más lo pasional que lo racional de la conducta, ya que la "educación en la familia y en la escuela es todavía anímica y no se ha integrado en una unidad más amplia, que es la educación para lo universal" (Naranjo, 1965, p. 243), por lo cual impera más la denominada "malicia indígena", el capricho y la intrepidez, que el razonamiento y la ponderación en situaciones apremiantes. E insiste el mismo autor en que "somos aún demasiado anímicos para haber cruzado ya el meridiano del espíritu" (p. 257) ${ }^{8}$, y que "nuestras pasiones cuentan más en los móviles de nuestra conducta que nuestras razones" (p. 256), a pesar de que esa herencia pasional proveniente de la raza peninsular se ha atenuado un poco por influencia de múltiples factores, por lo que seguimos siendo decididamente subjetivos y pasionales aún. Por este motivo gran parte de nuestras obras concretas "tienen mucha

7 Los análisis y conceptos de este autor son tenidos en cuenta y citados con frecuencia, dada su autoridad en estos temas. Sobre las diferencias de origen racial, dice Londoño (1955): "El guajiro cobrizo y el antioqueño con sus firmes líneas vascas; el costeño del Caribe con su arrogancia mulata y el huilense lento y enjuto; el africano vigoroso de nuestra costa del Pacífico y el santandereano de rasgos sajones; el nariñense con sus atributos quillasingas y el hombre del Cauca de distintivos castellanos, son tan diferentes entre sí como habitantes de continentes remotos" (p. 17). Esta diferenciación se manifiesta en las expresiones culturales como la música y el folclor y en los rasgos más específicos de su modo de ser, como se verá más adelante.

8 Estudia el tema desde el punto de vista sociopolítico 
alma pero carecen de espíritu cuando este se entiende como lo universal y lógico, aun cuando se crea que se hacen en nombre del espíritu y con muy poca lucidez sobre sus diferencias"' (p. 257).

\section{Lo andino-caribe como categoría de identificación del colombiano}

Aunque las anteriores apreciaciones tienen un alto grado de validez y objetividad, debemos, sin embargo, ubicarlas e interpretarlas dentro de un contexto geocultural concreto y limitado para poderlas utilizar como categorías de identidad cultural de los individuos y grupos a los que nos referimos en el presente estudio. Para este fin creemos útil apelar a la categoría andinocaribe como expresión de lo que Colombia es antropológica y culturalmente hablando, sin olvidar, lógicamente, otras influencias hereditarias y de mestizaje, y demás factores genético-evolutivos, históricos y sociales que han ayudado a configurar el alma de un pueblo y siguen ejerciendo influencia significativa sobre las actuales generaciones de colombianos.

Desde este punto de vista, y todavía dentro de una visión global de los rasgos peculiares del modo de ser de los colombianos, podemos considerar como válidas las siguientes apreciaciones del autor anteriormente citado:

Lo que es un hecho es que los colombianos participamos de dos estilos vitales y conviven en nuestra área dos maneras de encarar los problemas económicos, políticos y sociales: El estilo que pudiéramos llamar andino y el que pudiera denominarse caribe, siendo subordinado este último al primero. El acento que prevalece en nuestras manifestaciones espirituales, política, literatura, poesía, economía, es el andino, mesurado, sin apremios exuberantes, dueño de un equilibrio ponderado y enérgico, sin perder por eso el cálido aliento de la naturaleza caribe (Naranjo, 1965, p. 32).

Esta caracterización del modo de ser del colombiano varía, sin embargo, de una región geográfica a otra y da lugar a una múltiple combinación de modos de ser de connotaciones muchas veces antitéticas, como lo expresa el mismo Naranjo Villegas (1965) en los siguientes términos:

En general el hombre del interior, introvertido y meditabundo, está ahora en contacto con el de los litorales, extravertido (sic) y jocundo produciendo una actitud más abierta hacia el mundo. La expresión que domina, continúa siendo, sin embargo, la que da el acento andino, pero cada vez más vamos aproximándonos a lo que hemos llamado en otro capítulo el estilo andino-caribe que nos corresponde a los colombianos y que introduce una variedad de especie en el género de la cultura tropical.

En nuestros modos de ser se combinan el disimulo con la prudencia; la charlatanería con el deseo de agradar; la avaricia con la avidez; la desconfianza con la cautela; la crueldad con el valor; la vanidad con la servicialidad; la suciedad con la modestia; la impertinencia con la franqueza; la delación con la lealtad, en condiciones tan extrañas que se vacila muchas veces si se está delante de un héroe o de un bribón (pp. 255-256) ${ }^{9}$.

9 Con esta claroscura caracterización relaciona igualmente el autor la especial predisposición del pueblo colombiano para la política y cómo a veces se da colectivamente lo más noble o lo más abyecto según los estímulos y la conducción que reciban estas pasiones, de lo cual son muestras fehacientes y negativas los comportamientos de los grupos al margen de la ley, como las guerrillas, los paramilitares y otros de índole semejante (Cf. Naranjo, 1965, p. 256; Gutiérrez, 1966, pp. 11-56). 
Esta combinación contrastante de modos y comportamientos debe tener sus raíces y explicaciones antroposicológicas y sociohistóricas lo cual ameritaría una investigación más amplia y de carácter interdisciplinario de mayor complejidad. Esas raíces, sin embargo, han de ser tenidas en cuenta dentro de una interpretación del fenómeno cultural y religioso debido a sus implicaciones y condicionamientos, así como por sus consecuencias morales y sociales ${ }^{10}$.

Dentro de estas mismas coordenadas geoculturales de lo andino-caribe el profesor López de Mesa propone, con bases razonables, una caracterización antropológicocultural del pueblo colombiano siguiendo los procesos de poblamiento y mestizaje que históricamente han ocurrido y prosiguen aún en el país. Dentro de la respuesta a la pregunta que él mismo se plantea de cómo fue este poblarse y ser nación nueva nuestro país, avanza en su propuesta explicativa diciendo:

Por dicha distribución del poblamiento aparece hoy día el país dividido en dos porciones étnicas, que, grosso modo, pueden indicarse con una línea limítrofe de Ipiales, al sur, a Riohacha en el Atlántico, para ver que en la región oriental predomina el mestizo de criollo y aborigen, introverso y sutil, y en la occidental, el mulato de criollo y negro, extraverso, desenfadado, emprendedor. En compensación afortunada, el primero es más apto para las tareas culturales y profesionales afines, el segundo para la civilización técnica. Sino que este apartamiento, que ha producido en ocasiones mutua incomprensión y hasta guerras, desaparece poco a poco mediante el progreso vital, la migración interna y los negocios

10 Estos aspectos se refieren más que todo al campo especíico de la moral popular que no abordamos propiamente en este estudio.
(López de Mesa, 1970c, p. 111; 1970b, pp. 403-409, 412-416).

Insiste el mismo autor diciendo que en la banda occidental del mapa colombiano predomina el mulato aunque no haya desaparecido totalmente el elemento aborigen $\mathrm{y}$ que en el oriente predomina el mestizo física y espiritualmente (López de Mesa, 1970a, pp. 85-86). Dentro de estos dos grandes bloques en que el mencionado autor divide el país, señala que,

En la zona del oriente una tendencia a la cultura en profundidad, aunque todavía dificultada por el conflicto de la psicología aborigen, que donde esta raza prevalece aún no puede asimilar en temperamento, sino a ella meramente aproximarse en conducta, la ética tradicional hispano-romana, pero que en las mezclas avanzadas, que ya son la generalidad, se orienta hacia la introspección y a normas espirituales definidas (López de Mesa, 1970a, p. 86).

Mientras que en la zona occidental de Colombia se perciben ciertos síntomas de una especie de desviación hacia el predominio exagerado de las actividades económicas y hacia una cultura de superficie, entendiendo "por tal aquella que es al modo de un barniz de información en lo intelectual y una conducta de mera imitación en lo moral, no reacción espontánea del espíritu, no producto de un temperamento social definitivamente estructurado" (1970a, p. 86) ${ }^{11}$.

11 Hay que insistir en que se trata de tendencias que prevalecen o se exageran en una parte 0 en otra y que es difícil fijar objetivamente los rasgos predominantes y comunes ya que se trata de una realidad que evoluciona aceleradamente y que depende de diversos factores. "El carácter de un pueblo arranca de la triple raíz de la raza, el medio y la tradición. La raza fija las condiciones primarias, el medio las modela y la tradición las define y exalta. La historia nacional no es otra cosa que la concomitancia de estos tres factores en el espacio y en el tiempo; es la biografía de un pueblo proyectada hacia el futuro por estas tres fuerzas fundamentales". (Londoño, 1955, p. 9). A continuación el autor estudia, en el mismo escrito, cada uno de 
Dado el continuo proceso de cambio sociocultural que se advierte de manera diferente en cada región del país, debido a los complejos procesos de mestizaje, hay que relativizar cualquier sistema de clasificación que pretenda adentrarse en el campo de la sicología del hombre colombiano. Sin embargo, se deben tener en cuenta las advertencias que el profesor López de Mesa hace sobre los peligros que encierra o conlleva el extremar la llamada "cultura de superficie", por los resultados que aparecen en el comportamiento, tanto individual como grupal, acerca de lo cual dice:

Una cultura en superficie, cuando se extrema, confunde la vanidad con el orgullo, la agitación con la acción, el bullicio con la alegría, el derroche con la generosidad, la sensualidad con el amor, el tuteo con la amistad, la frase con la idea, el vestido con la distinción, el grito con el valor personal, el ver con el entender, el oír con el escuchar, el replicar con el responder, el predicar con el practicar, el censurar con el criticar, el comer con el alimentarse, el beber con el refrescarse, el divagar con el pensar, el leer con el estudiar, el castigar con el corregir, la exageración con la ponderación, la zalamería con la simpatía, la abundancia con la holgura, la fantasía con la imaginación, el talento con la inteligencia, el ingenio con el genio, la virtud con la fórmula [...] dicho así desordenada y tumultuosamente (López de Mesa, 1970a, p. 87) ${ }^{12}$.

La diferenciación de caracteres de las gentes de unas y otras regiones del país se puede

estos factores y su influencia en la determinación del carácter de los colombianos.

12 No hace falta insistir en que la conducta de los colombianos expresa muchas veces la confusión señalada en esta especie de letanía pareada, ni sobre sus implicaciones en el campo religioso y moral que exigiría un estudio a fondo de psicología socioreligiosa. Tampoco entramos a precisar cuándo se trata de modos de ser, actitudes hábitos, costumbres arraigadas, o solamente a modo de tendencias. concebir y explicar también, según el autor que venimos comentando,

como una polaridad de las funciones de un pueblo, mediante la cual el norte se opone al mediodía (septentrionales y meridionales) o el oriente al occidente, para predominar en una región el pragmatismo y en otra el idealismo, o la meditación y el impulso, o la alegría y la melancolía, etc. Esta relación de sur a norte es muy frecuente en $\mathrm{Eu}$ ropa. Entre nosotros se ha establecido de cordillera oriental a cordillera central, y así se explica el poco cariño que tienen los pueblos de una por los de la otra banda del río Magdalena, pues de tal divorcio de naturalezas surgen sentimientos e interpretaciones de la vida que tienen que chocar (López de Mesa, 1970a, p. 88) ${ }^{13}$.

Esta influencia de las condiciones geográficas y del paisaje ambiental sobre el carácter de los grupos humanos y su modo de ser parece bien expresada, aunque un poco míticamente y en lenguaje algo poético, en los siguientes aspectos:

La montaña separa y el río une; la planicie encierra una poderosa fuerza dispersiva y el valle una atracción aglutinante; los minerales fijan a los hombres como árboles y el pastoreo los vuelve transhumantes; la abundancia de riquezas naturales trae la molicie, y la esterilidad una actividad energética; la naturaleza indomable y bárbara de las regiones selváticas genera un terror que se aplaca solo con la intervención constante de los poderes divinos y la organización de la urbe moderna vuelve a

13 El autor pone ejemplos concretos de las dificultades que tradicionalmente hay para el trato entre los habitantes de una región a otra, y que Julio Londoño (1955) comenta en el mismo sentido al decir que, "Quizá en ninguna parte como en Colombia existe una animadversión más definida entre pequeñas regiones vecinas" (p. 12). Ejemplos en la página 13 de la misma obra. Esta animadversión se ha radicalizado de manera patética en las llamadas "barras bravas" del fútbol colombiano, y lo ha sido más aún entre "carteles regionales de la droga", en las últimas décadas. 
los hombres alejados de Dios; el mar abre la mente a la convivencia y a la innovación, a la alegría despreocupada y tolerante; la cordillera, en cambio, es un reducto para toda innovación, limita la sociabilidad, y vuelve al hombre reconcentrado, libertario y fanático; el clima frío adormece las pasiones y el cálido las exaspera como el alcohol; el aumento en latitud y en altura estimula la actividad y el pensamiento; su disminución acarrea la desidia y la superficialidad [...] y así indefinidamente (Londoño, 1955, pp. 11-12).

Sin embargo, hay otros factores que se deben tener en cuenta, como son los procesos de movilidad e integración social o simplemente el llamado contagio social que lleva al cambio de costumbres, formas de expresarse y de actuar ${ }^{14}$. Los distintos medios de comunicación social van también configurando el inconsciente colectivo, modelando nuevas conductas, influyendo sobre los valores, cambiando prioridades, criterios y vigencias que a la vez determinan o configuran formas de ser y de pensar de los grupos humanos.

Dentro de estas categorías geoculturales de lo andino-caribe, con toda la complejidad que implica, sus diferenciaciones, límites, matices y contrastes, también se puede interpretar la no menos compleja realidad de la religiosidad popular colombiana, para valorar mejor lo autóctono en la experiencia religiosa popular y en su proceso de evangelización, según lo ha expresado la Conferencia Episcopal de Colombia, desde hace

14 Por ejemplo, los múltiples desplazamientos de familias producidos por la violencia política y la presencia guerrillera en las distintas regiones del país (Guzmán, Fals Borda y Umaña, 1980, pp. 150-156, 294-300). Este proceso ha afectado y sigue afectando especialmente a los campesinos pobres, máxime por la acción del paramilitarismo y el narcotráfico de las recientes décadas. varias décadas (CEC, 1969, n. 245-246; Díaz, 1996).

\section{Claves para una tipología INTERPRETATIVA DEL "ALMA COLOMBIANA". UNA NARRATIVA SOCIOHERMENÉUTICA}

Para tratar de comprender cuál es el carácter del pueblo colombiano se podría hacer un estudio de psicología social o buscar en la literatura patria los rasgos de sus gentes y de los personajes simbólicos y representativos, o también buscar en la historia las constantes de su actuar, las formas de expresar sus sentimientos, sus creencias, sus vivencias, sus valores, y otros factores culturales. Aquí nos limitamos a considerar de forma narrativa algunas características del "modo de ser" de los colombianos según las distintas regiones y grupos humanos que componen el panorama colombiano. Al fijar nuestra atención en algunos aspectos diferenciales temperamentales de los grupos humanos en las distintas regiones del país podremos tener una clave más o menos válida para interpretar en su conjunto lo que se puede llamar el "alma colombiana". Ubicándonos en este ámbito geocultural tendremos ciertamente una mayor objetividad, aunque en nuestro caso se trata de una exposición sumaria y narrativa, siguiendo a quienes han estudiado con mayor detenimiento y amplitud esta compleja realidad del carácter y modo de ser del hombre colombiano ${ }^{15}$.

15 Básicamente seguimos los análisis y observaciones del profesor Luis López de Mesa, entresacando aquello que nos ha parecido más útil y cercano a nuestro propósito (Cf. 1970a, pp. 67-124); también, Instituto Geográfico Agustín Codazzi (1982); Marulanda, Octavio (1984); Ocampo López, Javier (1985); Naranjo Villegas (1965); Gutiérrez, José (1966); Ancízar, Manuel (1970); Londoño, Julio (1955, pp. 7 y Ss., 95 y ss.); Valencia Tovar (1977); Yunis Turbay (2003); Puyana García (2002). 


\section{Geografía de los grupos}

\section{humanos en el contexto andino colombiano, y su modo de ser}

- En una especie de recorrido narrativo y analítico por la región andina colombiana consideramos, en primer lugar, el grupo hispano chibcha, habitante de la planicie andina correspondiente a los actuales departamentos de Cundinamarca y Boyacá. En general es una población bastante uniforme en su conducta y temperamento, dada su mezcla de sangre ibérica y aborigen, que por su evolución sociocultural constituye en su conjunto algo así como "el centro medular de la cultura patria” (López de Mesa, 1970a, p. 78).

- En una aproximación general a sus rasgos anímicos peculiares, podemos fijarnos en los siguientes aspectos referidos a la población de ascendencia chibcha:

Lo más notorio de estas gentes es su exquisita sociabilidad, afabilidad y cortesanía, que siempre encuentran la frase oportuna y gentil para el que los visita, la hospitalidad para el extranjero, la caridad para el indigente, la generosidad para el amigo: virtudes que a veces se deforman hacia la hipocresía o el chisme social [...] Son espirituales, talentosos y plásticos. Se han mostrado sólidamente inteligentes en sus grandes representativos, con ser tan defectuosos los recursos culturales del medio ambiente, y entre sus hombres superiores figuran muchos mestizos de sangre indígena $[\ldots]$

El conjunto, sin embargo, no ha disciplinado o no ha equilibrado aún sus facultades: de ahí su curiosidad mental de información más que de organización de conocimientos [...] Por la plasticidad son adaptables; por la plasticidad y el talento son sutiles, cambian de opinión y están sujetos a entusiasmos fugaces (López de Mesa, 1970a, pp. 72-73).

El profesor López de Mesa enumera algunos rasgos más, tanto en sus aspectos positivos como en sus exageraciones y aspectos negativos. Por eso habla del disimulo y el mimetismo, la tendencia a la ironía, cierta falta de generosidad para calificar los méritos extraños y la función que desempeña el chiste en las relaciones sociales; también sobre cierto fondo taciturno y melancólico cuando prevalece lo indígena sobre lo andaluz, que se manifiesta en el vestir oscuro, en el hablar con suave entonación y ritmo lento, casi siempre en circunloquio, en asordinar la risa y el llanto, en reprimir la expresión de las emociones, en cultivar sus pasiones calladamente; son poco imaginativos en arte y más especulativos que creadores en ciencias, tienden a las profesiones conservadoras.

Pero como todos los colombianos buscan organizar sus opiniones en buen orden y bajo la clave de la autoridad legítima.

Excelentes camaradas, buenos miembros de familia, ciudadanos bien encauzados en su democracia, cultos en su expresión y deseosos de mejorar siempre, rinden un balance favorable a la desinteresada interpretación de su personalidad (López de Mesa, 1970a, pp. $73-75)^{16}$.

16 No parece necesario, sin embargo, enumerar aquí ciertos defectos y limitaciones tanto temperamentales como morales y culturales que alcanzan alguna gravedad en ambientes marginados y deprimidos, pero que forman igualmente parte de los comportamientos humanos, tanto en ésta como en las demás regiones del país. El mismo López de Mesa dice que "un hispano-chibcha tiene la psique como un bulbo de cebolla, que mientras más cortezas se le quitan más le aparecen en la intimidad y profundidad, casi indefinidamente" (López de Mesa, p. 88). 
Otro autor hace un pequeño balance diciendo:

Los campesinos cundinamarqueses son reservados, desconfiados como sus hermanos boyacenses, que pertenecen a la misma área cultural, y como ellos suelen ser crueles y tercos en sus determinaciones (Guzmán, Fals Borda y Umaña, 1980, p. 123; Fals Borda, 1961; Córdovez, 1942; Jiménez, 1967) ${ }^{17}$.

Para nuestro caso, basten estos datos sin entrar a determinar matices, causas y circunstancias que lógicamente le dan cierta relatividad a las afirmaciones sobre el modo de ser de las personas y de los grupos humanos en cuestión.

- Próxima a la región anterior están los otros pueblos de Boyacá y Cundinamarca que rodean en las vertientes oriental y occidental al grupo hispano-chibcha y que son descendientes de los grupos Muzos, Calimas y Panches, con bastante influencia caribe, que nos demuestran cómo la variación de sangre aborigen determina a su vez una sorprendente modificación de carácter. En efecto, estas

tribus guerreras que habitaron los países que dan frente al Magdalena desde Santander hasta el Tolima, Caribes del levante hasta las planicies remotas del Orinoco, nos dejaron mestizos de recia personalidad, selvática sin duda y desorientada aún, mas ciertamente preñada de porvenir. Esto nos explica en mucha parte la psicología del campesino que hoy habita esas regiones, su tendencia a la combatividad, sobre todo, su ánimo litigante, individualismo e indisciplina que tantas perturbaciones

17 Hay que tener en cuenta que dentro de este grupo y región la ciudad de Bogotá, más que formar parte del mismo, es, debido a su heterogeneidad poblacional, como ejemplo y resumen de lo que es $\mathrm{Co}$ lombia en sus múltiples aspectos, y que hoy es muy incierto hablar de los rasgos típicos del bogotano raizal (cachaco) como se hablaba hasta hace unas décadas. produce entre terratenientes y colonos, y a tanta delincuencia da ocasión (López de Mesa, 1970a, pp. 78-79).

A estos aspectos de índole genética hay que agregar la tradicionalmente caótica explotación de las minas de esmeraldas (en regiones de Boyacá) con todas sus secuelas, así como el secular marginamiento de estas regiones por falta de vías de comunicación, medios de desarrollo cultural y otros logros de la civilización y el progreso.

- A otro grupo pertenecen los habitantes de los dos Santanderes, descendientes principalmente de españoles, con poco mestizaje y casi ninguna influencia africana, a no ser en las márgenes del río Magdalena. Estuvieron rodeados por los muzos, guajiros y achaguas, tiene sangre remota de los chibchas, arhuacos y caribes y a su población pertenecen los motilones, chitareros, guanes, agataes y yariguíes, todos de ánimo batallador, nada sumisos ni pusilánimes. A pesar del poco mestizaje, "es posible, pues, pensar que el elemento aborigen que entra en la composición étnica del santandereano, por discreto que sea, traiga un vigor genético determinante que se impone en la psicología de ese pueblo" (López de Mesa, 1970a, pp. 80-85) ${ }^{18}$, ya que de otra manera conservaría puro el temperamento criollo iberoamericano. Pero en la configuración de su temperamento han influido también la geografía y las condiciones de vida en que se ha desarrollado, como lo afirma el citado profesor López de Mesa (1970a):

18 Sobre estos temas se pueden consultar, entre otros, a Gutiérrez (1940), Arias, (1947), Serrano (2001), Sierra (s. f.) y Arenas, (2006). También los distintos estudios sobre el movimiento revolucionario de los Comuneros suelen hablar sobre algunos rasgos anímicos y temperamentales de los santandereanos. 
Habita una región arriscada de pocas planicies, que va de uno a otro extremo subiendo y bajando serranías abruptas, espaciándose un segundo en la hoya profunda de sus ríos o de vez en cuando en las faldas de la cordillera, para formar un recodo donde asentar un pueblecito. Hasta estos últimos tiempos [...] ha vivido cuatro centurias aprisionado en sus riscos y aislado de la intensa relación que la economía y la cultura de un país requieren para progresar amplia y firmemente (p. 80).

Dice el mismo autor que este grupo racial es de aventajada estatura, de buen color, de acento agradable, que no tiene la débil inflexión fonética del bogotano, ni el acento explosivo del costeño, es de ritmo fonético garboso y preciso que parece arrogante cuando sólo es franco y pleno, con una recóndita musicalidad de canto (López de Mesa, 1970a) ${ }^{19}$;

es un pueblo introvertido, tímido y romántico, habituado a valerse por sí solo y a practicar cierta forma de autarquía, ha llevado una existencia atormentada y combativa desde antes de llegar los españoles, pasando por la revolución de los comuneros hasta las guerras civiles y los tiempos de la violencia política y guerrillera; por temperamento es altivo, independiente, individualista y laborioso, de voluntad recia, aunque

19 Álvaro Valencia Tovar describe a los santandereanos como "hombres delgados, hechos nervio y garra, rostros angulosos de donde escapa una mirada penetrante, arisca, orgullosa sin soberbia, vagamente retadora sin insolencia inútil. Raza forjada al sol y a la intemperie. Endurecida por el trabajo agrícola, en altiva pobreza que nace, vive y muere sobre los pegujales donde las plantas semejan imposible milagro. Es un tipo entre broncíneo y acerado, que solamente se logra tras de golpear larga y repetidamente sobre el yunque de las generaciones". "El ambiente y el hombre en la rebelión comunera", (Revista del Colegio Mayor de Nuestra Señora del Rosario, Bogotá, 514 [1981], p. 58): "El santandereano adusto, pensativo, individualista como si las barreras geográficas que se yerguen en torno a su existencia se interpusiesen puramente entre los hombres", "Dos contrastes colombianos" (López de Mesa). El autor compara el modo de ser de los santandereanos y los del Valle del Cauca por relación a su diverso contexto geográfico. sin un carácter bien disciplinado ni encauzado, con una irritabilidad permanente y cierta falta de control inteligente de sus pasiones (pp. 81-85).

Siendo gente altiva y dispuesta a defender sus derechos, es, sin embargo, también un pueblo acogedor y hospitalario, hogareño y generoso.

- Al otro lado del río Magdalena y en condiciones geográficas muy similares encontramos la región antioqueña ${ }^{20}$, junto con los actuales departamentos de Caldas, Quindío y Risaralda. Es un grupo racial profundamente modificado por el medio físico y las condiciones económicas en que ha vivido. Se distingue con absoluta nitidez de los demás grupos del país. Es un pueblo orgulloso de su raza, de sus montañas y de su lucha por hacer habitable y productiva una naturaleza arisca; los antioqueños ("paisas", popularmente) son generalmente emprendedores, "migradores" y comerciantes; de familias tradicionalmente numerosas y patriarcales, son activos, ambiciosos y fuertes y relativamente homogéneos en su carácter y costumbres; el antioqueño por lo general habla en voz alta y acciona abundantemente, su acento es desapacible y algo ingrato al oído por carecer de ritmo variado, articular mal algunos fonemas y acentuar descuidadamente la frase (López de Mesa, 1970a, pp. 94-105). Acerca de este pueblo dice Germán Guzmán: “Pueblo

20 Hay que recordar que desde la Colonia ha existido una especie de mito fluvial que considera al río Magdalena como la espina dorsal de la nacionalidad y eje divisorio de los grupos humanos, concepción que actualmente no parece corresponder a una realidad antropogeográfica, al decir del sociólogo e investigador Orlando Fals Borda, en Historia doble de la Costa, 4 vols., a lo cual se hace referencia en "La reorganización territorial: volviendo a las provincias y al federalismo" (Magazín Dominical, El Espectador, 131, 29 de septiembre de 1985, pp. 8-9). 
blanco-mulato eminentemente industrioso, frugal y piadoso, el antioqueño se ha distinguido entre los grupos colombianos por su dinamismo, sus altas tasas de fertilidad y sus emigraciones" (Guzmán, Fals Borda y Umaña, 1980, p. 137).

También el profesor López de Mesa (1970a) nos describe críticamente algunos rasgos del modo de ser de sus paisanos antioqueños:

Tímido y orgulloso a la vez es el antioqueño, mezcla que le perjudica grandemente, porque le priva de la flexibilidad del bogotano y de la agradable franqueza del costeño. Aventurero también, gusta de conocer el mundo, y es observador de mucha inquietud mental, aunque de información y en superficie todavía. No posee "humor", siquiera se le reconoce fama de chistoso, pues su gracejo es por exageración, al revés del bogotano que busca siempre el retruécano y el juego de las alusiones sutiles. Abusa del diminutivo para calificar las personas y las cosas, y sin embargo le embaraza expresar públicamente la ternura de sus íntimos afectos.

Conserva buena tradición de honradez, pero es ambicioso y un poco tahúr en los negocios. Progresista y civilista, ama la paz y la civilización material, presentando en esto un contraste insólito con el santandereano, porque siendo los dos tan semejantes en historia y medio ambiente, el uno, según lo anoté antes, es individualista, y el otro muy inclinado a un socialismo de estado, a un subordinarse a la autoridad, a la comunidad municipal, a su departamento, hasta el punto de que tiene "socializados" casi todos los servicios públicos de alguna entidad (p. 100) ${ }^{21}$.
El antioqueño ha sido un pueblo tradicionalmente pacifista y de fácil gobernación, aunque en las últimas décadas los problemas socioeconómicos e ideológicos lo han hecho frecuentemente convulso y violento, especialmente en sus generaciones más jóvenes y en las barriadas más populares de su capital. Como ha sido apegado a lo suyo, lo ha sido a su hogar, a su religión y a sus costumbres ancestrales y a los valores de su raza en un esfuerzo constante contra el aislamiento que le imponía una naturaleza montañosa y adversa:

Este es el milagro de aquellas gentes, dice López de Mesa, que así tan pobres y solitarias guardaron la lumbre de indeficiente aspiración a la remota cultura madre de que su ideal se nutrió casi por instinto. Siempre he preciado mucho esta vocación admirable del pueblo antioqueño a ennoblecer su estirpe con dones de espiritualidad a través de un sino adverso (López de Mesa, 1970a, p. 103).

Este aprecio, apego, exaltación y peculiar valoración de lo suyo, ha llevado, sin embargo, en gran medida, a que los "paisas", como se denomina a los antioqueños, a cultivar actitudes y comportamientos de exclusión hacia las gentes de otras regiones e, inclusive, a un regionalismo exagerado y en oportunidades violento.

- El grupo caucano que comprende actualmente los departamentos del Valle y del Cauca y que, en Popayán principalmente, fue el centro cultural, social, religioso y político de gran prestancia desde los primeros años de la Conquista hasta tiempos recientes, ha dado al país grandes personalidades en los distintos campos de la actividad a lo largo de la historia colombiana. Inclusive la ciudad de Popayán llegó a ser debido a su importancia 
una especie de segunda capital, o "segunda sede del espíritu patrio" (López de Mesa, 1970b, p. 413).

Así, como es variada su geografía y paisaje, también lo es su población que comprende núcleos de raza africana, sectores de predominio de los trigueños y conglomerados mestizos en procesos diferentes de desarrollo e integración. A este propósito, dice el profesor López de Mesa (1970b) que:

En la Colonia y durante los primeros ochenta años de nuestra vida republicana predominó en el antiguo Cauca una aristocrática minoría, noble de sangre y de conducta, de la cual son ejemplares sobresalientes los personajes antes mencionados como glorias del país; ocurrió luego una pausa racial, un silencio del espíritu, tal vez mientras se efectúa la blenda y se armonizan los elementos de un carácter uniforme, y ahora se ve surgir poco a poco el nuevo producto con muy diversa psicología (pp. 107-108) ${ }^{22}$.

Esta diversidad psicológica de los pobladores de esta región colombiana se observa especialmente en el conjunto que ofrecen las dos ciudades capitales, Cali y Popayán, que constituyen los dos grandes núcleos urbanos y que con ser tan cercanas manifiestan una diversidad sorprendente y un distanciamiento un poco desconfiado, que proviene quizá de la contrariedad de las razas y de sus procesos de evolución, como lo da a entender el autor que venimos citando:

Esta sorda contrariedad que las razas dominantes presentan en aquel crisol del Cauca es muy notoria en la psicología diferente que desarrollan las dos

22 El autor había mencionado antes a Francisco José de Caldas, Camilo Torres, José Joaquín Mosquera y sus dos hermanos (el General y el Arzobispo), los Arboledas, Figueroas, Mallarinos, Holguín, López, Valencia, Jorge Isaacs, etc. ciudades capitales Popayán y Cali. Recinto aquélla de una cultura evocadora, un poco apergaminada, clásica y latinista, poética y almenada espiritualmente, con un acento más castellano en la conducta y la fonética; criolla, económica y febril la segunda, de mayor vitalidad e inquietud emotiva y un acento sin 'll', (elle) con suave dejo tropical muy tenue y perceptiblemente altivo (Lópe de Mesa, 1970a, p. 109)23.

- Un poco más al Sur, limitando con Ecuador y bajo su constante influjo, está el pueblo de Nariño, distante y aislado casi siempre del resto de la nación colombiana, sin medios de cultivo intelectual ni campos de acción adecuados ni suficientes para su desarrollo, integración y progreso. En su composición racial predomina notoriamente la sangre indígena de los Quillacingas, aunque es difícil señalar lindes precisas entre el indígena puro y el descendiente de encomenderos españoles. Es un pueblo de índole marcadamente patriarcal, con abundancia de indigenismos y graciosas perturbaciones que aquejan su lenguaje, como el abuso del gerundio y el empleo del infinitivo verbal con desinencia diminutiva (por ejemplo, dicen 'andarcito', etc.). Es un pueblo de muy buena índoles, muy laborioso y hospitalario, aunque de mucha pobreza, puesto que ha vivido encerrado y aislado en su territorio y ha tenido que bastarse a sí mismo; es humilde y sosegado, aunque ha tenido

23 Así como Chaves y Puerta (1985). Hay que tener en cuenta también el influjo de los colonizadores antioqueños que llegaron hasta la región del Valle del Cauca y que después de cierto tiempo de rivalidades han logrado un entendimiento y compenetración beneficiosa. Álvaro Valencia Tovar dice que el habitante del Valle del Cauca es "alegre, risueño, extrovertido, fiestero, quizá algo trivial en ciertos rasgos adjetivos de su personalidad, exuberante como la naturaleza que lo rodea". "Dos contrastes colombianos". 
activa participación en las guerras civiles y algunos líderes belicosos.

El profesor López de Mesa (1974a) resume los rasgos más notorios y comunes de los nariñenses en los siguientes términos:

Considerando en su conjunto, el pueblo nariñense es amable, sobrio, delicado de maneras, suave de trato, valeroso en la guerra, laborioso en la paz, respetuoso de la tradición y del derecho, conservador y un poco fanático, cual es frecuente en aquellos grupos de nuestra población en quienes predomina la sangre aborigen, al revés de los en que (sic) supera el elemento de color [...] En la lucha por la independencia, mostrose asiduo defensor del gobierno peninsular, o más bien de su clero y caudillos regionales, y fue heroico en varias ocasiones $[\ldots]$

Dado a las ceremonias religiosas, como pueblo que no tiene otro ideal que la fe ni otra expansión del ánimo que la liturgia y las escenas populares del culto, asiste frecuentemente a procesiones, peregrinaciones y fiestas de esa índole; y hasta posee, a la manera del indígena boyacense, imágenes religiosas de renombre nacional (p. 115) ${ }^{24}$.

- Finalmente, hemos de considerar al antiguo departamento del Tolima, que comprende el Huila y una parte del Caquetá, cuya población es de origen hispano-caribe, como la de Santander, y tiene como antepasados a los Tamas, Paeces, Andaquíes, Pijaos, Pantágoras, etc., algunos de ellos de carácter altamente belicoso, lo cual, al decir del profesor López de Mesa (1970a),

24 En esta región desarrolló su polémico y conflictivo ministerio episcopal el obispo Ezequiel Moreno (1848-1905), canonizado por el Papa Juan Pablo II (1992), y allí mismo se halla el santuario mariano de Las Lajas, un importante centro religioso de peregrinación. explica en mucha parte el temperamento de este grupo, que si es patriarcal, hospitalario, honesto, sencillo, como cumple a un pueblo pastor de tradición cultural ibérica, es, sin embargo, altivo y guerrero indomable en horas de conflicto, franco y leal siempre, amén de liberal en política y muy amigo de la igualdad y la justicia, como era de esperarse en descendientes de tan altiva estirpe guerrera aborigen. De ahí que sus grandes hombres se hayan destacado en nuestra historia por su alteza moral y su apego a la democracia (pp. 117-120).

Desde otro punto de vista se dice también que "En términos generales, el tolimense se distingue por su temperamento alegre y cordial, expansivo y musical; es poco exigente y muy generoso" (Guzmán, Fals Borda y Umaña, 1980, p. 118) ${ }^{25}$, y de los huilenses se dice que son gentes sencillas, cordiales y algo ingenuas. Cualidades que se pueden resumir en los siguientes conceptos un tanto elogiosos pero a la vez expresivos de una realidad humana concreta:

Pueblo suave que en dejo quejoso de su acento arrulla la dignidad del hombre libre, el magisterio de la propia conciencia y el amor inefable a la patria: bajo su aparente debilidad encubre uno de los grandes caracteres de la República y de ella es y será vértebra de perdurable articulación nacional (López de Mesa, 1970a, p. 120).

Sobre los grupos humanos que habitan los Llanos Orientales, la Amazonía y la Orinoquía, no se conocen estudios consolidados sobre su composición étnica y cultural, bastante compleja y heterogénea, pero se puede decir que, en las últimas cinco décadas, por diversos factores económicos, sociales y

25 Las dos capitales, Ibagué y Neiva, son centros musicales y folclóricos de gran tradición y renombre nacional e internacional. 
políticos, han confluido en esas regiones familias y grupos de distintas partes del país y del vecino país de Venezuela, que han ido configurando lo que se ha denominado genéricamente como la "cultura del pueblo llanero", durante mucho tiempo marginado de la nacionalidad y en las décadas recientes convertidos en escenarios de una compleja conflictividad, lo que hace difícil expresar con algún acierto y objetividad sobre sus rasgos de carácter e idiosincrasia, manifestados especialmente en el campo musical y folclórico (Mantilla, 2002; Yunis, 2003, p. 54).

Puesto que el presente estudio se dedica principalmente a la región andina colombiana, no se explicitan o amplían más los aspectos de caracterización de los grupos caribes, pobladores de las costas del Atlántico que, de manera general, son más dados al arte y a la literatura, con un sentido muy arraigado de la fiesta, abiertos al mundo externo y receptores de las migraciones de otros pueblos y culturas a lo largo de toda la historia colombiana.

Estos son, a grandes rasgos y en términos narrativos, y sin pretender agotar los temas ni los enfoques, los principales grupos poblacionales y núcleos geoantropológicos y culturales que constituyen propiamente la región andina colombiana en su diversidad, y sobre los cuales versa principalmente el presente estudio.

\section{A MOdO DE CONCLUSIÓN: UNA IDIOSINCRASIA COMPLEJA Y EN DEVENIR}

El anterior recorrido geográfico y socioantropológico por las regiones de Colombia, en términos narrativos, nos ha aproximado al modo de ser del hombre colombiano, es- pecialmente en el ámbito de la región andina. Un mayor conocimiento de sus orígenes y evolución de sus condiciones físicas y ambientales, de sus procesos de integración y desarrollo, de sus experiencias históricas y de sus costumbres, nos ayudarían a comprender mejor, su evolución social, el mestizaje racial y su compleja realidad cultural, así como las diversas manifestaciones socioculturales en las que se expresan y a la vez se cultivan aspectos fundamentales de la identidad cultural. Habrá que tener siempre en cuenta que al hablar de Colombia nos enfrentamos a un fenómeno humano diverso por su diferente composición racial y por el medio físico en que se ha desarrollado, por la diversidad de costumbres y tradiciones que ha cultivado, aunque en proceso de integración progresiva y de relativa estabilidad social y política, como lo expresa el profesor López de Mesa:

Colombia ha logrado hoy día un cier-
to equilibrio, precario aún, de carácter,
una relativa estabilidad institucional,
una mejor comprensión de sus regio-
nalismos, un hálito de cultura autóc-
tona que emanan del avance de su
adaptación al medio geográfico y de la
lenta nivelación de su gente (citado en
Mantilla, 2002, p. 123)

Esta incipiente nivelación y equilibrio racial y social a la que ha llegado Colombia fue igualmente reconocida, en su momento, por los miembros de la llamada Misión de "Economía y Humanismo", en el estudio realizado sobre las condiciones del desarrollo del país bajo la dirección del Padre Louis Joseph Lebret, O.P. (1897 - 1966). En una de sus conclusiones, dice el citado estudio:

26 Aunque el mismo autor se pregunta si iremos hacia una elevada espiritualidad o sólo a una civilización de superficie. 
Colombia puede estar orgullosa de haber podido escapar a las manifestaciones agudas del problema racial y su experiencia en cuanto al respeto a todas las razas puede ser citado como ejemplo. A pesar de ello, enormes diferencias de orden fisiológico, psíquico y sociológico subsisten y subsistirán todavía por mucho tiempo, y se deben tener en cuenta para el desarrollo y la paz social. Temperamentos, niveles biológicos, facultad de adaptación, voluntad de trabajo, sentido de cooperación, nivel técnico, son muy distintos de una zona a otra y de un ambiente a otro (Misión Economía y humanismo, 1958, T. I, p. 370) ${ }^{27}$.

Dentro de esta unidad plural y multidiversa que es el hombre colombiano, tenemos que movernos al hablar de su carácter, de su modo de ser, de su temperamento, de su alma y de su idiosincrasia. Expresiones que hemos tomado para el caso en un sentido más o menos equivalente y que nos dan las bases antropológicas para comprender su identidad cultural. Dentro de esta diversidad de rasgos y temperamentos que se ha venido mencionando en el recorrido por las distintas regiones y grupos andinos colombianos, se pueden tratar de explicitar algunas características más o menos comunes y determinantes que ayudan a identificar la idiosincrasia colombiana.

En efecto, es fácil descubrir un conjunto de maneras de ser, sentir, actuar y pensar, que van desde los sentimientos de melancolía, agobio y frustración, hasta el tropicalismo fiestero desbordante que encuentra motivos constantes de regocijo y celebración ${ }^{28}$;

27 Sobre la persistencia del regionalismo y las rivalidades (Londoño, 1953, pp. 12-13).

28 El profesor Luis López de Mesa (1970a, pp. 59, 62) dedica una obra suya a estudiar las frustraciones del destino histórico en el suelo colombiano, y el poeta José Joaquín Casas escribió un largo poema sobre el sentido fiestero popular colombiano (Antología poética, Re- desde la obediencia dependiente, servil y acomplejada ante el autoritarismo paternalista, hasta el desorden, la indisciplina y la subversión; desde el altruismo humanitario, la generosidad y la compasión, hasta la tacañería, el resentimiento, la venganza y la crueldad; desde la proverbial simpatía, suavidad y amabilidad hospitalaria, hasta la desconfianza huraña, el disimulo y la envidia; desde la curiosidad, la versatilidad y la ocurrencia espontánea y creativa, hasta el fatalismo y el abandono pesimista; desde la paciente resignación y honda capacidad de sufrimiento, hasta la rebeldía e insolencia descontrolada; desde la desbordante generosidad solidaria ante las catástrofes y desgracias ajenas, hasta el más cerrado y egoísta individualismo; desde un romanticismo tierno, delicado y sensual, hasta el machismo violento, maltratador y esclavizante de la mujer; desde la timidez, la introversión y el aislamiento, hasta la imitación, el desparpajo, la ostentación y el despilfarro; desde la pereza y la ligera fatigabilidad ante el trabajo exigente, hasta la reciedumbre y tenacidad sacrificada que busca alcanzar una precaria subsistencia o amasar una cuantiosa fortuna; desde la paciente laboriosidad del campesino, del obrero y de las masas de seudoempleados, hasta la búsqueda de la riqueza fácil del banquero autoprestamista, del narcotraficante, del jugador de lotería y de las muchas formas de especulación, contrabando y economías subterráneas; desde la simpatía jovial y espontánea, hasta la ironía cruel, la burla despiadada y el

\footnotetext{
cuerdos de fiesta, pp.19-69), que termina: " $Q$ Qué presto que se evapora / Todo lo alegre en la vida!"; ambos sentimientos se expresan de modo semejante en los vernáculos versos de 'El Indio Rómulo' A propósito de estos temas se ha de tener en cuenta lo relacionado con la significación religiosa de la fiesta, su valor cultural y su relación con otros aspectos de la vida del pueblo.
} 
"mamagallismo" habitual ${ }^{29}$; en fin, desde la cortesía refinada, hasta la "chabacanería" y la vulgaridad en las palabras y en los gestos. Estos son algunos signos de las dicotomías abstrusas de la psicología colombiana y de la desarmonía temperamental de las gentes de este país andino caribe.

Esta compleja caracterización de la idiosincrasia colombiana se hace más notoria en un sentido o en otro, según prevalezca lo mestizo o lo mulato, junto a otros factores determinantes de la personalidad y estimulantes del comportamiento humano (López de Mesa, 1970a, p. 14; Jiménez, 1967, p. 77; Fals Borda, 1961, pp. 276-277; Londoño, 1955, pp. 157 ss; Otero, 1958, p. 25). Aquí suponemos, pero no explicitamos, cuánto hace la educación y los procesos culturales en la reforma y encauzamiento de la conducta de los individuos y de los grupos, ni de los cambios sociales que este proceso y las dinámicas globalizadoras va generando. Tampoco empleamos categorías valorativas para dar juicios sobre lo que parezca censurable o digno de encomio; se ha querido mantener el método narrativo-descriptivo que hemos adoptado y seguido en el presente estudio, sin que esto quiera esconder una actitud ingenua o descomprometida. Tampoco podemos entrar a considerar aspectos de orden genético relacionados con los comportamientos humanos y su moralidad (Flórez, 1959, pp. 45-70; Yunis, 2003).

A estas bases antropológicas tendremos que remitirnos con realismo y respeto los investigadores de la realidad social para comprender los comportamientos éticos, políticos y religiosos del pueblo, sus moti-

29 "Mamagallismo", y sus afines, es un vulgarismo popularizado por el escritor Gabriel García Márquez, equivale a "tomar del pelo", bromear, enfatizando lo burlesco, irónico y humorístico. vaciones, intereses y sus posibilidades de cambio y mejoramiento. Las políticas educativas tendrían más acierto si consultaran en profundidad las complejas raíces y vericuetos del alma y de la identidad e idiosincrasia colombiana. Desde estos presupuestos psicológicos y culturales podría también la Iglesia lograr, con mayor realismo, una interpretación teológica de la religiosidad popular colombiana y descubrir caminos quizá más autóctonos, creativos y eficaces en el proceso y metodologías de la evangelización liberadora, como lo ha sugerido el episcopado de Colombia, especialmente después del Concilio Ecuménico Vaticano II y de las últimas Conferencias Generales del Episcopado Latinoamericano (CEC, 1981, núms. 245-246) ${ }^{30}$. Conociéndonos mejor en lo que somos como pueblo y cultura, los colombianos podremos encontrar caminos más certeros y seguros para el desarrollo integral y equitativo, en convivencia pacífica, con sentido democrático e incluyente, proyección histórica, integración regional y sostenibilidad integral.

\section{Referencias}

Acuña, L. (1951). Refranero colombiano. Bogotá: Iqueima.

Aguilera, M. (2006). La rebelión de los comuneros. Bogotá: Panamericana.

Ancizar, M. (1984). Peregrinación de Alpha (t. I y t. II). Bogotá: Biblioteca Banco Popular. Arango Mejía, G. (1942). Genealogías de Antioquia y Caldas. Medellín: Imprenta Departamental.

30 A modo de ejemplo; igualmente en los documentos de las Conferencias de Medellín (1968), Puebla (1979), Santo Domingo (1992) y Aparecida (2007). 
Arciniegas, G. (2009). La libertad: el destino de América. Sus mejores escritos sobre la independencia, Bogotá: Planeta.

Ardila, R. (1986). Psicología del hombre colombiano. Cultura y comportamiento social. Bogotá: Planeta.

Arenas, E. (2006). Siete leguas: Proceso histórico de poblamiento y posicionamiento urbano en Santander. Bucaramanga: Universidad Santo Tomás.

Arias, J. (1947). El habitante. En Geografía económica de Colombia (t. VIII, 2a . parte). Bucaramanga: Imprenta Departamental.

Ballesteros, M. (1985). Cultura y religión de la América prehispánica. Madrid: BAC.

Bidegain, A. (Dir.) (2005). Historia del cristianismo en Colombia. Corrientes y diversidad. Bogotá: Taurus.

Bushnell, D. (1994). Colombia una nación a pesar de sí misma. De los tiempos precolombinos a nuestros días. Bogotá: Planeta.

Caballero, E. (1960). Historia privada de los colombianos. Bogotá.

Caballero, E. (1949). Cartas colombianas. Bogotá.

Chaves, Á. y Puerta, M. (1985). Tierradentro, Bogotá: El Áncora.

Clavijo, J. (Dir.). Identidad cultural del hombre colombiano (mecanografía, s. f., 53 folios). Bogotá: Universidad Santo Tomás, Facultad de Sociología, Centro de investigaciones.

Collins, F. (2009). ¿Cómo habla Dios? La evidencia científica de la fe. Bogotá: Planeta.

Conferencia Episcopal Colombiana, CEC. (1969). La iglesia ante el cambio. Bogotá: CEC.

Córdovez Moure, J. M. (1942). Reminiscencias de Santa Fe de Bogotá. Bogotá: Epígrafe.

De Aquino, T. (2003). El gobierno de los príncipes. Bucaramanga: Universidad Santo Tomás - Colección Universitas, 3.
Díaz, P. (1996). La religiosidad popular en la historia de Colombia. Aproximación histórica al catolicismo popular en los Andes colombianos. Bogotá: Códice.

Díaz, P. (2004). Competencias ciudadanas y Derechos Humanos. En las fronteras de la ética y la religión. Albertus Magnus, Revista interdisciplinar. I(III), 95-106.

Díaz-Plaja, F. (1969). El español y los siete pecados capitales. Madrid: Alianza.

Echeverry, A. (2005). Teología de la liberación en Colombia. Un problema de continuidades en la tradición evangélica de opción por los pobres. Cali: Universidad del Valle Anzuelo Ético.

Fajardo, L. (1966). ¿La moralidad protestante de los antioqueños? Estructura social y personalidad. Cali: Universidad del Valle.

Fals Borda, O. (1961). Campesinos de los Andes. Estudio sociológico de Saucío. Bogotá: Universidad Nacional de Colombia.

Fals Borda, O. (1981). Las revoluciones inconclusas en América Latina 1809-1968. (8ª . ed.). México: Siglo XXI.

Flórez, G. M. (1959). Aspectos sociológicos en la aparición y desarrollo de la conciencia moral, en Aliis Tradere, núm. 14, 45-70.

García Márquez, G. (1998). Por un país al alcance de los niños (Misión Ciencia, educación y desarrollo: Colombia al filo de la oportunidad). Bogotá: Tercer Mundo.

García Márquez, G. (2002). Vivir para contarla. Bogotá: Norma.

Gutiérrez, F. (1940). Santander y sus municipios. Reseña histórica del pueblo de Santander: 1529-1940. Bucaramanga: Imprenta Departamental.

Gutiérrez, J. (1940). Santander y sus municipios. Reseña histórica del pueblo de Santander. 1529-1940. Bucaramanga. 
Gutiérrez, J. (1966). Idiosincrasia colombiana y nacionalidad. Bogotá: Editorial Revista Colombiana.

Gutiérrez, V. (1968). Familia y cultura en Colombia. Bogotá: Tercer Mundo.

Guzmán, G.; Fals Borda, O. y Umaña, E. (1980). La violencia en Colombia. Estudio de un proceso social. Tomo I. Bogotá: Carlos Valencia Editores.

Ibáñez, J. (2010). La campaña de Boyacá. Bogotá: Panamericana.

Instituto Geográfico Agustín Codazzi (1982). Atlas básico de Colombia, Bogotá: Instituto Geográfico Agustín Codazzi.

Jaramillo, J. (1989). Ensayos de historia social. Bogotá: Tercer Mundo.

Jaramillo, J. (1994). La personalidad histórica de Colombia y otros ensayos. Bogotá.

Jiménez Cadena, G. (1967). Sacerdocio y cambio social. Estudio sociológico de los Andes colombianos, Bogotá: Tercer Mundo.

Jiménez, G. (1967). Sacerdocio y cambio social. Estudio sociológico de los Andes colombianos. Bogotá.

Londoño, J. (1955). Nación en crisis. Bogotá: Biblioteca de Autores Contemporáneos.

López de Mesa, L. (1970a). De cómo se ha formado la nación colombiana. Medellín: Bedout.

López de Mesa, L. (1970b). Disertación sociológica. Medellín: Bedout.

López de Mesa, L. (1970c). Escrutinio sociológico de la historia colombiana. Medellín: Bedout.

Mantilla, D. (2002). La tierra del joropo. Bogotá: Gente Nueva.

Marulanda, O. (1984). El folclor de Colombia. Práctica de identidad cultural. Bogotá: Artestudio.
Marzal, M. (1976). Diez hipótesis de interpretación del catolicismo popular. En Seladoc, Religiosidad popular. Salamanca: Sígueme.

Misión Economía y Humanismo (1958). Estudio sobre las condiciones del desarrollo en Colombia (t. I y t. II). Bogotá: Presidencia de la República.

Naranjo, A. (1965). Morfología de la nación colombiana. Aproximación a su antropología cultural (vol. XXII de la "Historia Extensa de Colombia", de la Academia Colombiana de Historia). Bogotá: Lerner.

Neira, C. (2004). Rostros y voces de Bogotá. Bogotá en la lente de los poetas. Poesía siglo XX. Bogotá: Universidad Nacional de Colombia.

Ocampo, J. (1985), Las fiestas y el folclor en Colombia. Bogotá: El Áncora.

Ocampo, J. (2007). La patria boba. Bogotá: Panamericana.

Ospina, W. (2003). ¿Dónde está la franja amarilla? Bogotá.

Ospina, W. (2007). América mestiza. El país del futuro. Bogotá: Aguilar.

Ospina, W. (2011). Por los países de Colombia. Ensayos sobre poetas colombianos. Bogotá: Fondo de Cultura Económica.

Otero, G. A. (1958). Vida social en el coloniaje. La Paz.

Parsons, J. (1960) La colonización antioqueña en el occidente de Colombia. Bogotá: Banco de la República.

Ponce, Á. (2010). De clérigos y generales. Crónicas sobre la guerra de los mil días. Bogotá: Panamericana.

Posada, E. (2006). La nación soñada. Violencia, liberalismo y democracia en Colombia. Bogotá: Norma. 
Puyana, G. (2002). ¿Cómo somos los colombianos? Reflexiones sobre nuestra idiosincrasia y cultura. Bogotá: Quebecor.

Restrepo, H. (1972). La religión de la antigua Antioquia. Estudio teológico-pastoral de Tomás Carrasquilla. Medellín: Bedout.

Revista Credencial (1996). El país que somos. Edición 121 (director Roberto GarcíaPeña).

Samper, D. (Selección y prólogo) (2003, 2004). Antología de grandes crónicas colombianas (t. I: 1529-1948, t. II: 19492004). Bogotá: Aguilar.

Santa, E. (2001). Raíces históricas de la cultura colombiana y otros ensayos. Bogotá: Academia Colombiana de Historia.

Serrano, M. (2001). El libro de la raza. Bucaramanga: SIC.
Sierra, E. (s. f.). Santander. Tierra con pasado, presente y futuro. Bucaramanga: Impresores Colombianos.

Uribe, C. (1992). La mentalidad del colombiano. Cultura y sociedad en el siglo XX. Bogotá.

Valencia Tovar, Á. (1977, 6 de enero). Dos contrastes colombianos. El Tiempo, 5-A.

Victoria, P. (2009). Grandes mitos de la historia de Colombia. La Nueva Granada contra España. Bogotá: Planeta.

Yunis, E. (2003). ¿Por qué somos así? ¿Qué pasó en Colombia? Análisis del mestizaje. Bogotá: Temis.

Zuluaga, F. (1981). Los campesinos colombianos. Bogotá: Pontificia Universidad Javeriana. 